\title{
Guttman Scale Analysis and its use to explain Cultural Evolution and Social Change
}

\author{
by Rochelle Forrester \\ Copyright (C) 2019 Rochelle Forrester \\ All Rights Reserved \\ The moral right of the author has been asserted
}

\begin{abstract}
Anyone may reproduce all or any part of this paper without the permission of the author so long as a full acknowledgement of the source of the reproduced material is made.
\end{abstract}

Second Edition

Published 30 September 2019

Preface

This paper was written to put the study of social and cultural history and social change on a scientific basis capable of rational analysis and understanding. This has resulted in a hard copy book How Change Happens: A Theory of Philosophy of History, Social Change and Cultural Evolution and a website How Change Happens Rochelle Forrester's Social Change, Cultural Evolution and Philosophy of History website. There are also philosophy of history papers such as The Course of History, The Scientific Study of History, and the Philosophy of History and papers on Academia.edu, Figshare, Mendeley, Vixra, Phil Papers, $\underline{\text { Humanities Common and Social Science Research Network }}$ websites.

The study of social and cultural history and social change includes a study of the history of science and technology due to the affect scientific and technological discoveries have on social and cultural history. A number of papers have been written on scientific and technological discoveries and the effect they have had on social change and cultural evolution and those papers are below:

The Invention of Stone Tools $\quad$ Fire The Discovery of Agriculture The Invention of Pottery

History of Metallurgy The Development of Agriculture and Pastoralism History of Writing

The Invention of Glass History of Astronomy Invention of Microscopes and Telescopes

History of Printing The Discovery of Steam Power History of Electricity

Electric Telegraph Telephone Radio Television Photography Motion Pictures

Internal Combustion Engine Motor Car Aeroplanes The History of Medicine

The Discovery of the Periodic Table The Discovery of the Atomic World

Other papers by Rochelle Forrester include works on Epistemology and the Philosophy of Perception such as Sense Perception and Reality and on quantum mechanics such as the Quantum Measurement Problem and The Bohr and Einstein debate on the meaning of quantum physics. Rochelle Forrester's work is also published on Slideshare, Issuu and Scribd. Rochelle Forrester is a member of the International Network for Theory of History. 


\section{Abstract}

Guttman scale analysis is a very useful tool to understand the evolution of societies. It shows the accumulation of cultural traits throughout history in various societies and that those cultural traits were usually accumulated in the same order. The results of studies, by Robert Carneiro and others, shows the accumulation of cultural traits is not random and indicates a universal pattern in cultural evolution. The universal pattern is caused by increasing human knowledge of the environment we live in. Human societies usually acquire this knowledge in the same order, with simpler discoveries concerning the natural world being made earlier than more complex discoveries. This means human social and cultural history, usually follows a particular course, a course that is determined by the structure of the human environment.

Guttman scale analysis is a method used in the social sciences, of dealing with binary information, that is information with a yes or no answer, where that information can be assembled in a particular order. An example of information that can be assembled in a particular order might be I can tolerate cats, I like cats, I would like to own a cat. Agreement with the last item implies agreement with the earlier items. A further example would be I know what numbers are, I can add numbers and I can do quadrilateral equations. Anyone who can do quadrilateral equations, must be able to add numbers and will know what numbers are. Equally anyone who knows how to add numbers must know what numbers are. This situation, where person A can say yes to the third proposition will also be able to say yes to the first and second propositions and person B who says yes to the second proposition will be able to say yes to the first proposition, while person $\mathrm{C}$ can only answer yes to the first proposition, can be arranged into a table. Such a table with plus signs representing a yes and minus signs a no could be as below.

Table A

\begin{tabular}{|c|c|c|c|}
\hline $\begin{array}{c}\text { adding } \\
\text { numbers }\end{array}$ & + & + & - \\
\hline $\begin{array}{c}\text { understanding } \\
\text { quadrilateral } \\
\text { equations }\end{array}$ & + & - & - \\
\hline $\begin{array}{c}\text { understanding } \\
\text { numbers }\end{array}$ & + & + & + \\
\hline & Person A & Person B & Person C \\
\hline
\end{tabular}

This table shows no particular pattern but can be arranged without changing the data by putting the most common proposition, understanding numbers in the bottom row, with the next most common proposition, adding numbers as the next row and the least common proposition understanding quadrilateral equations as the top row. The people can also be arranged with the least knowledgeable being listed first and with the one with the greatest knowledge last.

Table B

\begin{tabular}{|c|c|c|c|}
\hline $\begin{array}{c}\text { understanding } \\
\text { quadrilateral } \\
\text { equations }\end{array}$ & - & - & + \\
\hline $\begin{array}{c}\text { adding } \\
\text { numbers }\end{array}$ & - & + & + \\
\hline $\begin{array}{c}\text { understanding } \\
\text { numbers }\end{array}$ & + & + & + \\
\hline & Person C & Person B & Person A \\
\hline
\end{tabular}


This will produce a table like that above known as a scalogram. The scalogram has a stair step look known as a perfect scale with the number of pluses increasing as one moves from left to right through the people. The scaling effect is not caused by manipulating the data, it must be present within the data for it to appear. If one for example simply tossed a coin (heads for pluses and tails for minuses) and inserted the results from the coin tosses into a table, no matter how much the table was rearranged you would not get a stair step profile as is obtained above. This can be seen from the attached table with 3 sets of 6 coin tosses.

Table C

\begin{tabular}{|c|c|c|c|}
\hline 1 & + & - & + \\
\hline 2 & + & + & - \\
\hline 3 & - & + & + \\
\hline 4 & - & - & + \\
\hline 5 & + & - & - \\
\hline 6 & - & + & + \\
\hline & $\begin{array}{c}\text { First set of } \\
\text { tosses }\end{array}$ & $\begin{array}{c}\text { Second set of } \\
\text { tosses }\end{array}$ & $\begin{array}{c}\text { Third set of } \\
\text { tosses }\end{array}$ \\
\hline
\end{tabular}

Obviously there is no stair step profile here. Nor can a stair step profile be produced by moving the first, second or third set of tosses around or by changing the order in which the tosses are recorded in the left hand column. The actual results of the coin tosses cannot be changed as they represent the real data produced by tossing the coin and are equivalent to the data of the mathematical knowledge being shown in Tables A and B.

Why do we get the regular stair step result for the pluses in Table B when we could not get such a result from a random process, such as coin tosses. The stair step profile is caused by the data itself which is not random but which involves a process of accumulation. A person who knows how to do quadrilateral equations must also know how to add numbers and what numbers are. A person who knows how to add numbers must also know what numbers are. The person who knows what numbers are will not necessarily know how to add them or how to do quadrilateral equations. The different levels of knowledge is reflected in the number of pluses in the table which can be arranged in the stair step scalogram pattern. The process of accumulation is not present in the data produced by the coin tosses. Each coin toss is a separate act unrelated to the other coin tosses.

Guttman scale analysis has been used by anthropologist Robert Carneiro to show both the complexity or degree of evolution of a society and the sequences by which societies develop certain traits. The type of traits Carneiro investigated were the development of stone tools, copper, bronze and iron metallurgy, the use of pottery, the domestication of plants and animals, the development of writing and numerous other traits. In his article Scale Analysis, Evolutionary Sequences and the Rating of Cultures Carneiro actually deals with as many as 618 cultural traits all involving pre-industrial societies.

Guttmam scale analysis involves listing the societies chosen for the analysis along the bottom of a sheet of graph paper and the cultural traits along the side of the graph paper. As many or as few societies or traits as desired may be used. Societies and traits can be listed in an arbitrary order. If a particular trait is present in a society it is indicated by a plus sign $(+)$ on the graph paper and if it is absent it is indicated with a minus sign (-).

A simple such analysis will produce a table such as is shown below. 
Table D

\begin{tabular}{|l|c|c|c|c|}
\hline $\begin{array}{l}\text { settlements } \\
\text { of } 100+\end{array}$ & + & - & + & + \\
\hline food surplus & + & - & + & + \\
\hline $\begin{array}{l}\text { social } \\
\text { stratification }\end{array}$ & + & - & + & - \\
\hline iron tools & + & - & - & - \\
\hline & Romans & Tasmanians & Inca & Iroquois \\
\hline
\end{tabular}

Such a table can be rearranged with the most common traits being listed at the bottom of the traits and the least common at the top. The societies can also be rearranged with the societies with the fewest traits being listed first and the one with the greatest number listed last. This will produce a scalogram like that below.

Table E

\begin{tabular}{|l|c|c|c|c|}
\hline iron tools & - & - & - & + \\
\hline $\begin{array}{l}\text { social } \\
\text { stratification }\end{array}$ & - & - & + & + \\
\hline food surplus & - & + & + & + \\
\hline $\begin{array}{l}\text { settlements of } \\
100+\end{array}$ & - & + & + & + \\
\hline & & & & \\
\hline
\end{tabular}

There is something about the societies and traits which gives this particular stair step pattern. The pattern is derived due to the order in which the societies have derived the cultural traits. The traits in the lower part of table E were derived earlier than those on the top part of the table and due to this more societies have those traits. If one examines the traits from bottom to top that is the approximate order in which the traits are accumulated in societies. Settlements of 100+ and food surpluses (both with 3 pluses) began about 10,000 years ago, social stratification began soon after food surpluses and iron tools developed last (around $1200 \mathrm{BCE}$ with the invention of iron smelting by the Hittites). We arrange the table to have the most common traits at the bottom and the least common at the top and this coincides with the actual historical order societies acquired the traits. This must be because the traits occurred in the order in which they are shown in the above table. Any sample of societies and traits that have actually existed should show the stair step profile regardless of whether the samples are selected or are random. The only restrictions on this are that the traits selected should be retained in the societies over the long term and should arise in approximately the same order in different societies in which they exist. If they arose in different orders scaling would fail and the fact that scaling is usually successful indicates that the traits tend to arise in various societies in very similar order.

If scaling occurs then certain things can be said about the societies and traits involved. Societies in the right hand column have all the traits that other societies have and some additional ones as well. If a particular trait is present in a society, we can predict that it will have certain other traits. A society with iron tools can also be predicted as having social stratification, food surpluses and settlements of over 100 people. If a trait is absent from a society, then we can predict other traits will also be absent. If a society does not have a food surplus, it will not have social stratification or iron tools. If we know a society's highest and lowest traits we can predict whether a society has any other trait. The highest trait for the Inca is "social stratification" and the lowest is "settlements of 100+". This means we can also say the Inca will also have food surpluses but not iron tools. If we know the number of traits a society has we can say what they will be. If a society has just two traits they will be "settlements of more than 100 people" and "food surpluses".

The reason why scaling works in cultural evolution is because traits will usually accumulate within a society over time leading to societies developing greater complexity over time. If traits 
accumulated over time, then over time societies acquire more traits. Over the same period of time society A may develop 1 trait, society B 3 traits, society C 5 traits and society D 6 traits represented by $1,3,5$ and 6 pluses as shown on the table below.

Table F

\begin{tabular}{|c|c|c|c|c|}
\hline 6 & - & - & - & + \\
\hline 5 & - & - & + & + \\
\hline 4 & - & - & + & + \\
\hline 3 & - & + & + & + \\
\hline 2 & - & + & + & + \\
\hline 1 & + & + & + & + \\
\hline & Society A & Society B & Society C & Society D \\
\hline
\end{tabular}

When societies develop a trait it is usually not lost so societies with trait 6 will normally have the previous 5 traits as well as trait 6 . If societies did not retain traits then a random pattern would be produced much like with coin tosses which can not be arranged in a stair step pattern.

Perfect scaling is rarely achieved and various means have been developed to measure the degree of scaling. The most common such method is known as the coefficient of reproducibility. The coefficient of reproducibility measures the degree to which we can predict which items a society will have if we know the number of traits it has. To measure the coefficient of reproducibility we total the number of traits whose presence or absence would have been wrongly predicted from each society's scaling. The total number of these errors is divided by the product of the total number of traits and societies in the scalogram. This will produce a decimal fraction which when subtracted from one gives the coefficient of reproducibility.

The formula for the coefficient of reproducibility is

number of errors

$1-$

traits $\mathrm{x}$ societies

The product of traits $\mathrm{x}$ societies is simply the number of results from the yes or no question as to whether a society has a particular trait or not. It is the number of pluses and minuses contained in the table and coefficient of reproducibility involves a comparison of the number of errors against the total number of pluses and minuses in the table.

An example of the calculation of the coefficient of reproducibility can be seen from the table below.

Table G

\begin{tabular}{|l|l|l|l|l|l|l|}
\hline 6 & - & - & - & - & - & + \\
\hline 5 & - & - & - & - & + & + \\
\hline 4 & - & - & - & - & + & + \\
\hline 3 & - & - & - & + & - & + \\
\hline 2 & - & - & + & - & + & + \\
\hline 1 & - & + & + & + & + & + \\
\hline & A & B & C & D & E & F \\
\hline
\end{tabular}

The number of errors for society D is 2 as it does not have trait 2 and it has trait 3 when it only has a total of 2 traits. Society E also has 2 errors as it does not have trait 3 and it has trait 5 when it only has 4 traits. This gives 4 errors in total which becomes the numerator while the denominator is the product of traits $\mathrm{x}$ societies as is shown below. 


\section{4 \\ $1-$ \\ $6 \times 6$}

Perfect scaling produces a coefficient of 1.00 while no scaling at all produces a coefficient of 0 . Depending on what societies and traits are used scaling seems to be typically above .90 while if traits arose in random order in societies the scaling would be 0 . It is not necessary for scaling to be 1.00 to indicate there is something in the data that needs explaining, anything above 0 indicates a pattern for which there must be some sort of causal factor. The causal factor for scaling above 0 is that societies do actually acquire traits in a similar order. The reasons societies acquire traits in a similar order is because they have similar problems and similar resources at their disposal to solve those problems. They discover how to develop and use those resources in a similar order of discovery.

There may be a number of reasons why perfect scaling with a coefficient of 1.00 does not always occur. Societies like the Aztecs and Maya of Central America did not have large domesticable animals available to them so they could never develop traits such as plough agriculture or wheeled transport. Societies in areas with no copper, tin or iron deposits could not develop cooper, bronze or iron metallurgy. Agriculture was never going to be developed by the Inuit, Laplanders or by desert dwellers. Lack of large domesticable animals, plough agriculture, wheeled transport and metallurgy will certainly ensure that the Central American civilizations will develop traits in a different order from Old World civilizations.

A further reason for traits being developed in different orders in different societies concerns the diffusion of traits. Traits will spread from one society to another so the order in which they are acquired may vary greatly depending upon whether or not diffusion takes place. A society open to the diffusion of traits such as Japan after the Meiji Restoration or Russia from the time of Peter the Great will acquire traits in a different order from societies that are resistant to diffusion, such as Ottoman Turkey and Tokugawa Japan. Some societies, such as some Islamic societies, may be open to receiving some traits, for example those involving technology, but may be reluctant to accept other traits such as those involving political systems or social organization.

How traits are expressed will also effect scaling. The trait "tool use" scales effectively while a trait of "use of stone tools" does not scale as it is lost when stone tools are superseded by more efficient metal tools. Absolute monarchy will only scale to such time as when it has not been superseded by democratic institutions. Where traits are superseded rather than accumulated, they will not scale well. However the new traits can appear on the scalogram in replacement of the superseded traits.

The accuracy of the description of traits can have an effect on the accuracy of scaling. It may be somewhat uncertain as to whether a particular society has a trait or not. Do modern Scandinavian societies have religion? A few people in those societies do, but most do not. Does one say a society has religion when 1 person does and millions do not? Some societies will be in a state of transition from not having a trait to acquiring the trait or from having the trait to losing the trait. The same problem can arise from what is a society? Does a society have agriculture when it imports all its food. No society is truly separate from other societies, yet we treat them as separate societies when doing scale analysis.

If factors such as lack of particular resources, diffusion, how traits are expressed and the accuracy of trait description are taken into account then it may be possible to produce perfect scaling with a coefficient of 1.00 . The exclusion of traits that do not scale well could provide valuable information as to what extent human social and cultural developments are necessarily unilateral and to what extent it is multilateral. Traits which do scale effectively would indicate unilateral development as they are acquired in the same order in many or all societies, while those that do not scale well are acquired in different sequences in different societies indicating multilateralism. 
Bibliography:

Carneiro, Robert (1968) Ascertaining, Testing and Interpreting Sequences of Cultural Development, Southwestern Journal of Anthropology 24:354-374

Carneiro, Robert (1969) The Measurement of Cultural Development in the Ancient Near East and in Anglo-Saxon England, Transactions of the New York Academy of Sciences 31: 1013-1023

Carneiro, Robert (1962) Scale Analysis as an Instrument for the Study of Cultural Evolution, Southwestern Journal of Anthropology 18:149-169

Carneiro, Robert (1970) Scale Analysis, Evolution Sequences, and the Rating of Cultures in $A$ Handbook of Method in Cultural Anthropology, ed Raoul Naroll and Ronald Cohen, 834-871

Peregrine, Peter N, Ember, Carol R and Ember, Melvin (2004) Universal Patterns in Cultural

Evolution: An Empirical Analysis Using Guttman Scaling, American Anthropologist 106(1):145-149 